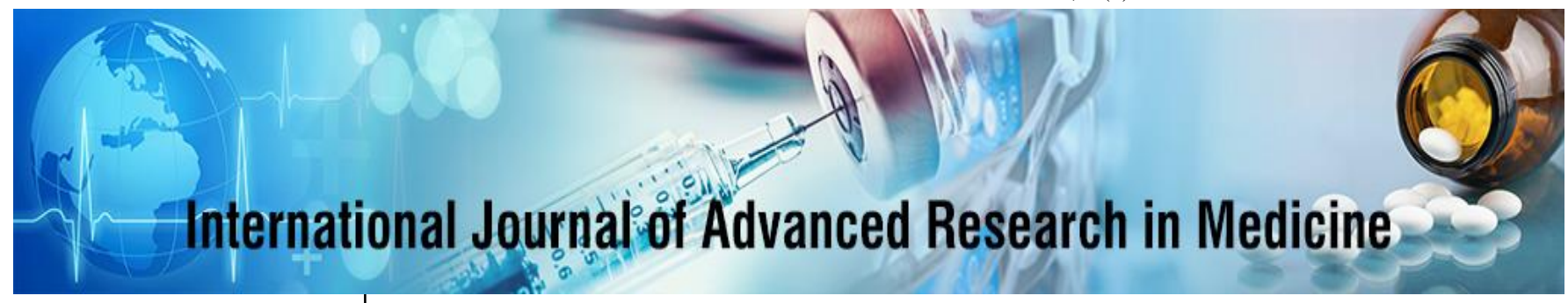

E-ISSN: 2706-9575

P-ISSN: 2706-9567

IJARM 2021; 3 (1): 510-514

Received: 04-01-2021

Accepted: 06-03-2021

Dr. Venu Akkala

Assistant Professor,

Department of Paediatrics,

Kakatiya Medical College,

Warangal, Telangana, India

Dr. Banothu Sudhakar

Assistant Professor,

Department of Paediatrics,

Kakatiya Medical College,

Warangal, Telangana, India

Corresponding Author:

Dr. Venu Akkala

Assistant Professor,

Department of Paediatrics,

Kakatiya Medical College,

Warangal, Telangana, India

\section{A study of bacteriological profile in neonatal sepsis in neonatal intensive care unit in a tertiary care centre}

\author{
Dr. Venu Akkala and Dr. Banothu Sudhakar
}

DOI: $\underline{\text { https://doi.org/10.22271/27069567.2021.v3.i1i.193 }}$

\begin{abstract}
Background: Septicaemia in neonates refers to a generalized bacterial infection in the first four weeks of life that is confirmed by a positive blood sample. It is one of India's four leading causes of neonatal death and morbidity.

Aim: To study the bacteria responsible for neonatal sepsis in Neonatal Intensive Care Unit in a tertiary care centre.

Methods: 100 neonates with symptoms and signs suggestive of sepsis were included in this study. A written informed consent was taken from either of parents of the babies who were included in the study. All babies included in the study were subjected to detailed maternal and neonatal history taking. A detailed clinical examination of the new born was done and gestational age was assessed by New Ballard's score chart and the findings recorded in the pre-structured proforma.

Results: In the present study, out of the 100 cases with symptoms and signs suggestive of sepsis, 23 cases $(23 \%)$ were culture positive. Klebsiella pneumoniae was isolated in $2(28.58 \%)$ cases and Enterococcus in 2 (28.58\%) of cases, Staph. aureus-Coagulase +ve in 1 (14.28\%) cases, Pseudomonas spp. in $1(14.28 \%)$ cases, Enterobacter spp. in 1 (14.28\%) cases isolated indicating that Klebsiella pneumoniae was the most frequent organism isolated in late onset sepsis. Enterobacter and Enterococcus were isolated only late onset sepsis and not seen in early onset sepsis.

Conclusion: Klebsiella pneumoniae and Staph. aureus-Coagulase +ve are the leading cause of neonatal sepsis in this study and most of them are resistant to multiple antibiotics. Therefore the results of this study suggest that, surveillance of antimicrobial resistance in our hospital is necessary.
\end{abstract}

Keywords: sepsis, septicaemia, Klebsiella pneumoniae, Staph. aureus

\section{Introduction}

Neonatal sepsis is a clinical syndrome characterized by signs and symptoms of infection with or without accompanying bacteraemia in the first month of life. It encompasses various systemic infections of the new born such as septicaemia, meningitis, pneumonia, arthritis, osteomyelitis, and urinary tract infections ${ }^{[1]}$.

According to pooled hospital data based on National Neonatal Perinatal Database 2002-2003 (NNPD) survey, the incidence of neonatal sepsis around is 30/1000 live births. Neonatal infections are estimated to cause, about 1.6 million deaths worldwide and $40 \%$ of all neonatal deaths due to sepsis occur in developing countries ${ }^{[2]}$.

The Mortality rate due to neonatal sepsis in developing countries is $26 \%{ }^{[1]}$. Neonatal sepsis contributes significantly to morbidity and mortality among young infants. Classically sepsis has been differentiated into early onset and late onset sepsis based on onset before 72 hours or later life up to 28 days. These 2 types of sepsis have different risk factors or settings. Clinical outcome varies in neonatal sepsis. Early onset sepsis is caused by organisms prevalent in the genital tract or in the labour room and maternity operation theatre. Mainly early onset sepsis was caused by E. coli, Group B Streptococci (in west), Klebsiella sp., Staph. aureus. (NNPD Report 2002-2003). ${ }^{[2]}$ Late onset sepsis was caused by of gramnegative bacilli (Klebsiella pneumoniae, E. coli, Pseudomonas aeruginosa, Proteus spp., Citrobacter, Enterobacteria) in two-thirds of cases ${ }^{[3-9]}$.

Bacterial responsible for neonatal sepsis varies from place to place and also from time to time. Antibiotics have been used extensively in the management of sepsis. On many occasions, antibiotics have been used empirically without identifying the causative organisms or knowing the antibiotic sensitivity, leading to development of resistance. It is therefore necessary to note which are the common organisms causing sepsis in our area 
and their sensitivity to antibiotics. This will help us to use appropriate antibiotics and reduce the development of antibiotic resistance. Hence this study has been conducted to identify the organisms causing sepsis in the new born and to determine the antibiotic sensitivity pattern of common bacteria isolated in our area.

\section{Materials and Methods}

The present study was a hospital based prospective observational study conducted in Neonatal Intensive Care Unit, Department of Paediatrics,

Period of study: From January 2019 to December 2020.

Study sample: All babies admitted to Neonatal Intensive Care Unit with the clinical suspicion of sepsis were taken up for the study. Sepsis was clinically suspected if the neonate had symptoms and signs suggestive of sepsis ${ }^{[1]}$ such as poor feeding, poor activity - respiratory distress, retractions, nasal flaring, apnea. cyanosis. - seizure, lethargy, bulging anterior fontanel - fever, hypothermia - Abdominal distension, vomiting, jaundice.

Sample size: 100 neonates with symptoms and signs suggestive of sepsis.

\section{Inclusion criteria}

All babies admitted to the Neonatal Intensive Care Unit, with symptoms and signs suggestive of sepsis.

\section{Exclusion criteria}

- Babies who received antibiotics previously.

- Babies with major congenital anomalies.

- Very low birth weight $(<1500 g m s)$

\section{Methodology}

The present study was approved by the institutional ethics committee, prior to the start of the study.

A written informed consent was taken from either of parents of the babies who were included in the study. All babies included in the study were subjected to detailed maternal and neonatal history taking. A detailed clinical examination of the new born was done and gestational age was assessed by New Ballard's score chart and the findings recorded in the pre-structured proforma.

All the Data related to history, clinical findings and investigations was entered in pre-structured proforma.

Statistical analysis: The data was managed on the Microsoft Excel spread sheet. All the entries were checked and the data was analysed using SPSS software version 21 .

Ethical clearance: Ethical Clearance was taken from the institution ethical clearance committee prior to the commencement of the study.

\section{Observation and Results}

Table 1: Distribution based on gender, birth weight, gestational age and age of onset

\begin{tabular}{|c|c|}
\hline Gender & Number of babies n (\%) \\
\hline Male & $73(73)$ \\
\hline Female & $27(27)$ \\
\hline Total & $100(100)$ \\
\hline \multicolumn{2}{|c|}{ Birth weight } \\
\hline $1500 \mathrm{gms}-2500 \mathrm{gms}$ & $59(59)$ \\
\hline$>2500 \mathrm{gms}$ & $41(41)$ \\
\hline \multicolumn{2}{|c|}{ Gestational age } \\
\hline Preterm & $64(64)$ \\
\hline Term & $36(36)$ \\
\hline \multicolumn{2}{|c|}{ Age of onset } \\
\hline Onset $<72$ hours (Early onset) & $83(83)$ \\
\hline Onset $>72$ hours (Late onset) & $17(17)$ \\
\hline
\end{tabular}

In the present study, out of the 100 neonates admitted in the Neonatal Intensive Care Unit with clinical suspicion of sepsis, $73(73 \%)$ of the babies were males and $27(27 \%)$ were female babies, indicating that male babies constituted a majority.

In the present study, out of the 100 new-borns studied, 59 (59\%) babies weighed less than 2500gms and 41 (41\%) babies weighed $\geq 2500 \mathrm{gms}$, indicating that there is a predominance of low-birth-weight babies weighing $<2500 \mathrm{gms}$.

In the present study, $64(64 \%)$ babies admitted with clinical suspicion of sepsis were preterm, and $36(36 \%)$ were term, indicating that majority of the babies studied were preterm and almost double the number of term babies.

Table 2: Distribution based on investigations, bacterial growth and blood and urine culture

\begin{tabular}{|c|c|}
\hline Investigations & Number of babies (\%) \\
\hline C-reactive proteins $>1 \mathrm{mg} / \mathrm{dl}$ (positive) & $87(87 \%)$ \\
\hline Abnormal total count & $40(40 \%)$ \\
\hline$<5000 / \mathrm{mm}^{3}$ & $25(25 \%)$ \\
\hline $15000 / \mathrm{mm}^{3}$ leukocyte & $15(15 \%)$ \\
\hline Platelet count $<1$ lakh/dl & $32(32 \%)$ \\
\hline Culture Positive & $23(23 \%)$ \\
\hline Culture Negative & $77(77 \%)$ \\
\hline \multicolumn{2}{|c|}{ Bacterial growth } \\
\hline Blood culture positive & $21(91.30 \%)$ \\
\hline Urine culture positive & $2(8.70 \%)$ \\
\hline
\end{tabular}


Haematological investigations done in the babies having symptoms and signs suggestive of sepsis showed that $\mathrm{C}$ reactive protein was found to be positive in $87 \%$ cases. Total Leukocyte count was abnormal in $40 \%$, out of these $25 \%$ babies had less than $5000 / \mathrm{mm}^{3}$ and $15 \%$ babies had more than $15000 / \mathrm{mm}^{3}$. Thrombocytopenia (Platelet count < 1 lakh) was seen in $32 \%$ cases.

In the present study, out of the 100 cases with symptoms and signs suggestive of sepsis, 23 cases (23\%) were culture positive and in $77 \%$ cases, organisms were not grown.

In the present study, out of 100 cases studied, 23 cases had bacterial growth, in which 21 cases $(91.30 \%)$ were blood culture positive and 2 cases $(8.70 \%)$ were urine culture positive for bacterial growth. Cerebrospinal Fluid (CSF) culture was done in all blood culture positive cases and clinically suspected meningitis, but CSF culture revealed no growth of organisms.

Table 3: Distribution of cases based on bacteria isolated and onset of sepsis

\begin{tabular}{|c|c|c|c|}
\hline Onset of sepsis & Gram positive sepsis n (\%) & Gram negative sepsis n (\%) & Total cases n (\%) \\
\hline$<72$ hours Early onset sepsis & $5(21.74)$ & $11(47.82)$ & $16(69.56)$ \\
\hline$>72$ hours Late onset sepsis & $3(13.04)$ & $4(17.40)$ & $7(30.44)$ \\
\hline Total cases & $8(34.78)$ & $15(65.22)$ & $23(100)$ \\
\hline
\end{tabular}

Chi-square $=0.0038, \mathrm{P}$ Value $=0.47$

Out of 23 cases with positive culture, Gram negative organisms were predominantly isolated comprising of 15 cases $(65.22 \%)$. 8 cases $(34.78 \%)$ had isolated Gram positive organisms. Culture positivity in early onset sepsis was $69.56 \%$ compared to late onset sepsis, where only $30.44 \%$ was culture positive. $\mathrm{P}$ value is 0.47 which is not significant.

Table 4: Distribution of cases of type of bacteria isolated and bacterial culture positivity based on the onset of sepsis

\begin{tabular}{|c|c|c|}
\hline Bacteria isolated N = 23 & Early onset sepsis N = 16 (\%) & Late onset sepsis N = 7 (\%) \\
\hline Staph. aureus - coagulase +ve & $3(18.75)$ & 0 \\
\hline Coagulase -ve Staph. aureus & $2(12.50)$ & $2(28.58)$ \\
\hline Enterococcus & 0 & 0 \\
\hline Esherichia coli & $2(12.50)$ & $2(14.28)$ \\
\hline Pseudomonas spp. & $1(6.25)$ & 0 \\
\hline Klebsiella pneumonia & $5(31.25)$ & 0 \\
\hline Citrobacter & $1(6.25)$ & $1(14.28)$ \\
\hline Acinetobacter & $2(12.50)$ & $7(100)$ \\
\hline Enterobacter & 0 & $168)$ \\
\hline Total & $16(100)$ & \\
\hline
\end{tabular}

In the present study, 23 babies had shown growth in the culture. In the 23 babies with culture positivity, the predominant organism isolated was Klebsiella pneumonia (30.43\%), followed by Staphylococcus aureus (17.39\%), Esherichia coli (8.7\%), Pseudomonas spp. (8.7\%), Acinetobacter (8.7\%), Coagulase -ve Staph. aureus (8.7\%), Enterococcus (8.7\%), Citrobacter (4.34\%), Enterobacter (4.34\%).

In the present study, out of 16 cases of Early onset sepsis, Klebsiella pneumoniae was isolated in 5 (31.25\%) of cases, Staph. aureus - Coagulase in $3(18.75 \%)$ cases, Coagulase negative Staph. aureus in $2(12.50 \%)$ cases, Esherichia coli in $2(12.50 \%)$ cases, Pseudomonas spp. in 1 (6.25\%) cases,
Citrobacter in $1(6.25 \%)$ cases and Acinetobacter in 2 $(12.50 \%)$ cases, indicating that Klebsiella pneumoniae was the most frequently grown organism in Early onset sepsis. In the present study, out of 7 cases of late onset sepsis, Klebsiella pneumoniae was isolated in $2(28.58 \%)$ cases and Enterococcus in 2 (28.58\%) of cases, Staph. Aureus Coagulase +ve in $1(14.28 \%)$ cases, Pseudomonas spp. in 1 (14.28\%) cases, Enterobacter spp. in 1 (14.28\%) cases isolated indicating that Klebsiella pneumoniae was the most frequent organism isolated in late onset sepsis. Enterobacter and Enterococcus were isolated only late onset sepsis and not seen in early onset sepsis.

Table 5: Antibiotic sensitivity pattern in gram positive and gram negative isolates

\begin{tabular}{|c|c|}
\hline \multicolumn{2}{|c|}{ Sensitivity of gram positive organisms } \\
\hline Antibiotic & $\mathrm{n}(\%)$ \\
\hline Vancomycin & $7(87.5)$ \\
\hline Ciprofloxacin & $7(87.5)$ \\
\hline Linezolid & $4(50)$ \\
\hline Cefotaxime & $4(50)$ \\
\hline Amikacin & $4(50)$ \\
\hline Gentamicin & $3(37.5)$ \\
\hline Co-trimoxazole & $1(25)$ \\
\hline \multicolumn{2}{|c|}{ Sensitivity of gram negative organisms } \\
\hline Antibiotic & Number $(\%)$ \\
\hline Ciprofloxacin & $13(86.66)$ \\
\hline Gentamycin & $12(80)$ \\
\hline Amikacin & $12(80)$ \\
\hline
\end{tabular}




\begin{tabular}{|c|c|}
\hline Meropenem & $8(53.3)$ \\
\hline Piperacillin/tazobactem & $4(33.3)$ \\
\hline Cefotaxime & $4(33.3)$ \\
\hline Ceftazidime & $3(26.6)$ \\
\hline Vancomycin & $2(13.3)$ \\
\hline Amoxycillin clavulanate & $2(6.7)$ \\
\hline
\end{tabular}

In the present study, out of the 8 cases which had grown Gram positive organisms, 7 cases $(87.5 \%)$ were sensitive to vancomycin and ciprofloxacin, 4 cases $(50 \%)$ were sensitive to linezolid, amikacin and cefataxime, 3 cases $(37.5 \%)$ to Gentamycin and only 1 case was sensitive to co-trimoxazole (25\%).

In the present study, Gram negative isolates were most sensitive to ciprofloxacin $(86.6 \%)$, followed by gentamycin (80\%) amikacin (80\%), meropenam 53.3\%, piperacillin/tazobactem $33.3 \%$, cefataxime $33.3 \%$, and $26.6 \%$ to ceftazidime. Gram negative isolates had low sensitivity to amoxycillin-clavulanate $(6.7 \%)$.

Table 6: Distribution of cases in the present study based on outcome

\begin{tabular}{|c|c|}
\hline Out come & No. of babies N (\%) \\
\hline Recovered/Discharged & $97(97)$ \\
\hline Death & $3(3)$ \\
\hline
\end{tabular}

In the present study, out of the 100 neonates admitted with sepsis, 97 (97\%) babies recovered, whereas 3 babies i.e. 3\% had died.

\section{Discussion}

In the study done by Pooja et al. ${ }^{[10]}$ the gram-negative organisms were susceptible to Imipenem (86.13\%), Meropenem $(83.22 \%)$, piperacillin/tazobactam $(76 \%)$ and fluroquinolones $(74.5 \%)$. These findings are not comparable with this study, where Ciprofloxacin was sensitive in $86.6 \%$ of cases and Meropenems are sensitive only in $53.3 \%$ cases. In the study done by Bhatt $\mathrm{S}$ et al. ${ }^{[1]}$ the antibiotic sensitivity pattern revealed that the majority of Gramnegative isolates (Klebsiella species and Escherichia coli) were sensitive to Meropenem (95\% and 97\%), Piperacillin and tazobactam (88\% and 91\%), Levofloxacin (84\% and $81 \%$ ) and Ampicillin and sulbactam (58\% and 49\%) respectively and these findings are not comparable with this present study in where meropenem sensitivity was only $53.3 \%$ and Piperacillin and tazobactam only $33.3 \%$.

In the present study gram negative organisms were sensitive to ciprofloxacin which is comparable with the studies done by Pooja et al. ${ }^{[10]}$ and Bhatt $\mathrm{S}$ et al. ${ }^{[11]}$. Gram negative organisms were highly sensitive to Amikacin in the present study and was comparable to studies done by Pooja and Bhatt $\mathrm{S}$ et al. Cefotaxime sensitivity was low in this study comparing with Pooja and Bhatt et al. explanation for this could be this drug being used as empirical treatment in neonatal sepsis in our Neonatal Intensive Care Unit.

In the present study gram negative bacteria were sensitive to Ciprofloxacin, Amikacin and Gentamycin which was not comparable with the studies done by Premalatha ${ }^{[12]}$ and Shivakumar ${ }^{[13]}$. Wherein the gram-negative bacteria were more sensitive to Imipenem's and resistance to Gentamycin and Amikacin.

A study done by Srinivasa et al. Gram-positive group had greater susceptibility to higher antibiotics vancomycin $97 \%$, linezolid $91.2 \%$, cephalosporin $84 \%$, quinolones $70.1 \%$ in order and low susceptibility to ampicillin $31.5 \%$ these findings were comparable with present study ${ }^{[14]}$.

In study done by Desai et al. ${ }^{[15]}$ Gram positive isolates were maximum sensitivity to Vancomycin (100\%). Gram negative isolates were maximum sensitivity to Piperacillintazobactam (98\%). These findings were not comparable to the present study in where Gram negative isolates were more sensitive to Ciprofloxacin, Gentamycin, Amikacin. In our study, Klebsiella was the commonest organism grown which was highly sensitive to Amikacin, Gentamicin and Ciprofloxacin.

This study was having limitations with regard to the sample size. A larger sample size would be better to derive the bacteria responsible for sepsis and the antibiotic sensitivity in our area.

\section{Conclusion}

In this study, Klebsiella pneumoniae and Staph. aureus Coagulase +ve were the most common causes of neonatal sepsis. The majority of them are immune to a variety of antibiotics. As a result, the authors recommend that antimicrobial resistance be monitored. In addition, the hospital should develop an antibiotic policy. Antibiotics should be used based on the isolates' antibiotic susceptibility pattern. Furthermore, we recommend that the public be educated about the risks of indiscriminate antibiotic usage, which is still considered a threat in our community and has been linked to the ineffectiveness of most widely used antibiotics like penicillin and ampicillin, as found in our research.

\section{References}

1. Sankar MJ, Agarwal R, Deorari AK, Paul VK. Sepsis in new born. Indian J Pediatr 2008;75(3):261-266.

2. National Neonatal Perinatal Database. Report Year of 2002-2003. National Neonatal Forum, India 2005. http://www.newbornwhocc.org/pdf/nnpd_report_20022003. PDF Accessed on 23/2/2021.

3. Singh M. Perinatal infections. In: Care of newborn. $8^{\text {th }}$ edition. Sagar publication, New Delhi 2014, 223-230.

4. State of India's new-borns 2014, 31-32. http://newbornwhocc.org/SOIN_pdf.PDF. Accessed on 27/2/2021.

5. Stoll BJ. Infections of neonatal the neonatal infant. In: Robert MK, Bonita FS, Nina FS (Editors). Nelson`s Textbook of paediatrics. $20^{\text {th }}$ edition. Philadelphia, Saunders 2015, 629-648.

6. Chandrasekaran A. Early neonatal sepsis -what is new. Indian J Pediatr 2014;16(3):278-283.

7. Ramesh R, Deorari AK, Paul VK. Sepsis In Newborn, AIIMS Protocols 2014, 1-13.

8. http://www.newbornwhocc.org//clinical_proto/pdfneon atology 2014.PDF

9. Karen MP. Bacterial and Fungal infections. In: Cloharty JP, Eicheenwald EC, Stark AR (edtr). Manual of Neonatal Care. $7^{\text {th }}$ edition. New Delhi, Wolters Kluwer (India) Pvt. Ltd 2010, 274-278. 
10. Avery GB, Fletcher MA, Macdonald MG. Neonatal bacterial sepsis. In: Avery's diseases of new-born. $5^{\text {th }}$ edition. Philadelphia, Lippincott William \& Wilkins 2010, 465-473.

11. Pooja R, Sowmya KN, Shrikala B, Radhakrishna M, Keerthiraj B. A Spectrum of Bacterial Pathogens and its Antibiotic Susceptibility Pattern Isolated from Neonatal Sepsis in an NICU in a Government Paediatric Hospital. International Research Journal of Biological Sciences 2015;4(5):50-54

12. Bhatt S, Patel D, Gupta P, Patel K, Joshi G. Bacteriological profile and antibiogram of neonatal septicemia. National Journal of Community Medicine 2012;3(2):238-241.

13. Premalatha ED, Koppad M, Halesh HL, Siddesh CK, Prakash N. The bacterial profile and antibiogram of neonatal septicaemia in a tertiary care hospital. International journal of recent trends and technology 2014;10(3):451-454.

14. Shivakumar S, Bhurle A. Neonatal Septicemia Isolates and Antibiotic Susceptibility Pattern in a Tertiary Care Hospital in North Karnataka. International Journal of Health Information and Medical Research 2014;1(3):25-29.

15. Srinivasa S, Arunkumar D. Bacterial isolates and their Antibiotic susceptibility patterns in Neonatal sepsis. Curr Pediatr Res 2014;18(2):83-8.

16. Desai KJ, Malek SS, Parikh A. Neonatal septicemia: Bacterial isolation \& their antibiotic sensitivity patterns. I.M.A.G.S.B. News Bulletin 2010;6(2):510-517. 